Recepción: 10/ 09 / 2018

Aceptación: 22 / 11 / 2018

Publicación: 03 / 12 / 2018

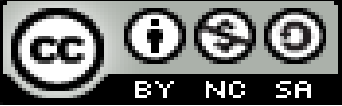

Ciencias de la educación

Artículo de investigación

\title{
La enseñanza de la música. Una estrategia pedagógica para la educación inclusiva
}

\section{The teaching of music. A pedagogical strategy for inclusive education \\ O ensino da música Uma estratégia pedagógica para a educação inclusiva}

\begin{abstract}
Oscar E. Bolívar-Chávez ${ }^{\text {I }}$
obolivar@utm.edu.ec
\end{abstract}

Vicente F. Véliz-Briones II

vfveliz@utm.edu.ec

Andrea K. Alcívar-Cedeño ${ }^{\mathrm{III}}$

aalcivar@utm.edu.ec

\section{Correspondencia: obolivar@utm.edu.ec}

\footnotetext{
${ }^{\text {I }}$ Máster en Nuevas Tecnologías Aplicadas a la Educación, Licenciado en Ciencias de la Educación Especialidad Instrumentista Pedagogo en Saxofón, Docente de la Universidad Técnica de Manabí, Portoviejo, Ecuador.

II Magíster en Informática, Doctor en Ciencias Técnicas, Ingeniero en Electricidad Especialización Electrónica, Docente de la Universidad Técnica de Manabí, Portoviejo, Ecuador.

III Magíster en Telecomunicaciones, Ingeniero en Sistemas Computacionales, Tecnólogo Programador, Docente de la Universidad Técnica de Manabí, Portoviejo, Ecuador.

IV Magíster en Gerencia Educativa, Licenciada en Ciencias de la Educación Técnica Mención Contabilidad Computarizada, Docente de la Universidad Técnica de Manabí, Portoviejo, Ecuador.

${ }^{v}$ Magíster en Educación y Desarrollo Social, Ingeniero Comercial, Docente de la Universidad Técnica de Manabí, Portoviejo, Ecuador.
} 


\section{Resumen}

La música posee una indudable importancia para la educación y para ser aplicada como Estrategia pedagógica, por esta razón la enseñanza con el recurso de la música en el proceso enseñanza-aprendizaje, debe ser puesto en práctica armonizado con el contenido temático, en forma sencilla, además, ayudados con los recursos musicales que permita cumplir con esta necesidad, que es de todos los educandos, educadores y hasta de la misma comunidad. Bajo esta premisa, el presente artículo devela información teórica en términos de inclusión educativa y de los beneficios de la enseñanza musical en el desarrollo y aprendizaje integral de los educandos. La metodología fue de tipo descriptiva, con un enfoque epistemológico hermenéutico, en la que revisaron diferentes teorías relacionadas con el uso de la música como una estrategia de enseñanza aprendizaje en el nivel de educación básica escolar. La población estuvo constituida por 120 docentes de los distintos colegios de educación básica adscrito a la provincia de Manabí. El instrumento utilizado fue una lista de cotejo semi-estructurado, el cual estuvo constituido por 8 ítems. Además, se observaron el ambiente pedagógico de las aulas de los distintos colegios visitados, así como la disposición de materiales de uso musical. Los resultados del análisis de la información obtenida permitieron concluir que existe la necesidad manifiesta, por parte de los docentes investigados, de recibir cursos de formación musical en materia del uso de la misma como estrategias de facilitación para el proceso de enseñanza aprendizaje de sus alumnos.

Palabras clave: música; enseñanza -aprendizaje; estrategias pedagógicas; educación inclusiva; docente de educación básica.

\section{Abstract}

Music has an undoubted importance for education and to be applied as a pedagogical strategy, for this reason teaching with the use of music in the teaching-learning process must be put into practice harmonized with the thematic content, in a simple way, also, helped with the musical resources that allow to meet this need, which belongs to all the students, educators and even the community itself. Under this premise, this article reveals theoretical information in terms of educational inclusion and the benefits of music education in the development and integral learning of students. The methodology was descriptive, with a hermeneutical epistemological approach, in which they reviewed different theories related to the use of music as a teachinglearning strategy at the level of basic school education. The population was constituted by 120 
teachers of the different schools of basic education attached to the province of Manabí. The instrument used was a semi-structured checklist, which consisted of 8 items. In addition, the pedagogical environment of the classrooms of the different schools visited was observed, as well as the disposition of materials for musical use. The results of the analysis of the information obtained allowed us to conclude that there is a manifest need, on the part of the investigated teachers, to receive musical training courses on the use of the same as facilitation strategies for the teaching-learning process of their students.

Key words: music; teaching learning; pedagogical strategies; inclusive education; teacher of basic education.

\section{Resumo}

A música tem uma importância inegável para a educação e para ser aplicado como estratégia pedagógica, portanto, ensinar com o uso da música no processo de ensino-aprendizagem deve ser colocado em prática harmonizado com o conteúdo temático, simplesmente, também, ajudou com os recursos musicais que permitem atender a essa necessidade, que pertence a todos os alunos, educadores e até a própria comunidade. Sob essa premissa, este artigo revela informações teóricas em termos de inclusão educacional e os benefícios da educação musical no desenvolvimento e aprendizagem integral dos alunos. A metodologia foi descritiva, com abordagem epistemológica hermenêutica, em que foram revisadas diferentes teorias relacionadas ao uso da música como estratégia de ensino-aprendizagem ao nível do ensino básico. A população foi constituída por 120 professores das diferentes escolas de ensino fundamental vinculadas à província de Manabí. O instrumento utilizado foi uma lista de verificação semiestruturada, composta por 8 itens. Além disso, foi observado o ambiente pedagógico das salas de aula das diferentes escolas visitadas, bem como a disposição de materiais para uso musical. Os resultados da análise das informações obtidas levaram à conclusão de que há uma necessidade manifesta por parte dos professores pesquisados, recebendo cursos de formação musical na sua utilização como estratégias de facilitação para o processo de ensino-aprendizagem de seus alunos.

Palavras chave: música; ensino-aprendizagem; estratégias pedagógicas; educação inclusiva; professora de educação básica. 


\section{Introducción}

A pesar de que existen cientos de condicionantes escolares para lograr una total inclusión, esta tarea es tan complicada como necesaria. Por eso, son las instituciones educativas uno de los medios más importantes para potenciar esta inclusión, dado que las nuevas generaciones serán las encargadas de cambiar una sociedad, en muchos casos, maltratada por los adultos. Pues, hablar de inclusión educativa, es integrar al alumno en el aula y dar respuestas necesarias a ese alumnado. Se trata de un modelo de institución educativa, según la UNICEF (2001), en la que no existen requisitos de entrada ni mecanismos de selección o discriminación de ningún tipo, para hacer realmente efectivos los derechos a la educación, a la igualdad de oportunidades y a la participación.

De acuerdo con lo recabado, entendemos que la inclusión educativa implica cambiar el enfoque que tienen los docentes sobre la educación, remover los cimientos de la misma y estructurarla de nuevo para que todos los pertenecientes a una propuesta pedagógica tengan los mismos derechos y posibilidades de llevarla a cabo y participar de esta manera en igualdad de condiciones en el proceso de enseñanza-aprendizaje. Para ello, al considerar que todos los alumnos tienen diferencias, necesidades y capacidades diferentes es una ventaja propia de aquel docente que propone un proyecto de aprendizaje inclusivo.

Al respecto, los docentes deben estar preparados para diseñar actividades que promuevan la inclusión. Dentro de estas actividades, la música es una guía excepcional en los procesos de enseñanza aprendizaje, haciendo de estos un momento de libertad y disfrute junto con sus compañeros. Los docentes han olvidado que la música es una joya que el entorno les brinda para conocer los sentimientos de sus alumnos, sus diferencias, así como para educar su sensibilidad. Por ello, desempeñan un papel muy importante en el proceso enseñanza -aprendizaje, en el entendido que muchas veces el aprendizaje no llega igual a cada alumno, cada individuo aprende de acuerdo a su propio ritmo, de allí, la necesidad de aplicar otras técnicas y recursos que faciliten una mejor comprensión de los contenidos planteados. Si el docente utiliza música en el quehacer diario correlacionando con los objetivos propuestos del plan de estudio, facilita la adquisición de nuevos aprendizajes y estimula a la vez, el desarrollo de habilidades cognoscitivas: memoria, comprensión y capacidad de respuesta y lógica. 
Soledad y Carvajal (2015), explican que La música ha sido, es y será una de las mayores herramientas educativas para los docentes por sus múltiples beneficios, así como motor de la dinamización de actividades, permitiendo el alto disfrute de los alumnos mediante este recurso educativo. Un tema tan amplio como es la música necesita ser desglosado para de esta manera poder analizar cada una de las bases que hacen de ella una herramienta para la inclusión. De allí que la música ha sido, es y será una de las mayores herramientas educativas para los maestros, por sus múltiples beneficios, así como motor de la dinamización de actividades, permitiendo el alto disfrute de los alumnos mediante este recurso educativo. Una vía para lograr el proceso aprendizaje sería entonces, la música como recurso pues esta, favorece la interacción grupal, a la vez enriquece la imaginación y permite el desarrollo de conductas abiertas hacia el aprendizaje. Por lo tanto, en este artículo se expone de manera extractada, información teórica para ahondar en términos de inclusión educativa el análisis de los beneficios de la enseñanza musical en el desarrollo y aprendizaje integral de los educandos.

\section{Desarrollo}

Está comprobado, según González (2008), que la música desarrolla la atención, la concentración, la memoria, la tolerancia, el autocontrol, la sensibilidad; que favorece el aprendizaje de la lengua, de las matemáticas, de la historia, de los valores estéticos y sociales; que contribuye al desarrollo intelectual, afectivo, interpersonal, psicomotor, físico y neurológico. La deficiencia que se advierte en el rendimiento de determinadas materias, como las matemáticas o la lengua, se puede resolver a través de la educación musical. Por otro lado, Díaz (2014) afirma que "existe un paralelismo entre los tres componentes de la música (ritmo, melodía y armonía) y los tres niveles de complejidad humana (ámbito socio-afectivo, cognitivo y psicomotriz) siempre que consideremos que el ser humano se divide en tres partes (cuerpo, corazón y pensamiento)” (p.6).

\section{La música como estrategia pedagógica}

La utilización de la música pasa de ser un complemento de uso cotidiano a utilizarse como estrategia en el aprendizaje. La tarea de enseñar puede hacerse de una forma distinta a la tradicional, que sea menos estresante y que no se haga de la enseñanza algo obligatorio sino más bien un proceso consciente, agradable, motivador, tanto para quien recibe la enseñanza como para el que la imparten. 
En este sentido, Montero (2011) explica que aunque el Proceso de aprendizaje en los alumnos está condicionado por una serie de factores de cierta complejidad relacionada con su condición personal, ambiental, genética, de recursos, y de método, la dificultad para alcanzar el dominio cognoscitivo no está en la capacidad para aprender, sino en la forma de cómo se orienta el aprendizaje, La capacidad para aprender puede desarrollarse, pero la dirección para que el sujeto aprenda es cuestión de tecnicismo psicopedagógico. Esa forma de orientar el aprendizaje puede fácilmente acompañarse de estrategias que incluyan la música. El recurso musical no es ajeno, en el contexto social encontramos antecedentes en los cuales se utilizó la música desde la prehistoria con propósitos ceremoniales y de culto y que hoy en día aún se utilizan, incluso antes de que el hombre crease los instrumentos ya hacía música, probablemente cantando, aplaudiendo o golpeando objetos.

Según Díaz (2003) la estrategia de aprendizaje está formada por: "procesos de toma de decisiones (conscientes e intencionales) en las cuales el alumno elige y recupera, de manera coordinada, los conocimientos que necesita para complementar una determinada demanda u objetivo, dependiendo de las características de la situación educativa en que se produce la acción." Por su parte González (2008), indica que el uso de estrategias en el proceso enseñanza - aprendizaje conduce hacia: La promoción de un aprendizaje efectivo, permiten secuenciar, ordenar y trabajar con exactitud los contenidos para un mejor aprovechamiento, evitan la improvisación, dan seguridad a los actores (educando, educador), favorecen la autoconfianza, fomentan el trabajo cooperativo, dinamizan el proceso de enseñanza-aprendizaje, favorecen la participación y socialización, evitan la memorización mecánica del material docente, el alumno deja de ser receptor para ser el actor de sus propios aprendizajes y es gestor de sus conocimientos.

\section{Efectos Físicos y psicológicos de la música}

Varias investigaciones han demostrado los efectos especiales que la música ha tenido sobre las personas. López (2007) relata que la música se ha caracterizado, a lo largo de la historia, por producir en el ser humano efectos en diferentes niveles implicando lo biológico, sociológico, espiritual, intelectual, social y psicológico. "La música nos relaja, nos distiende, nos causa placer, nos puede alterar, ensordecer, estimular, excitar, alegrar, entristecer, nos puede traer recuerdos, permitirnos hacer asociaciones, recordar momentos, enojarnos, etc. 
Bernabeu y Goldstein (2009) afirman que la música tiene un dominio de evocación superior al de las imágenes y a pesar de que el ser humano está inmerso en lo visual, las personas tienen en la memoria determinados esquemas sonoros unidos a estados emocionales. Estos autores recomiendan que, si se hace un buen uso de la música, se puede llegar a tener efectos muy beneficiosos tanto para el cuerpo como para la mente. Entre los efectos que causa la música, mencionan que: Puede acelerar o ralentizar el ritmo cardíaco en las personas. Debido a la secreción de las hormonas también puede producir cambios metabólicos. De igual manera puede alterar el ritmo respiratorio, causar cambios en el sistema inmunitario, en el tono muscular y en la temperatura basal. Puede modificar la actividad neuronal en las zonas del cerebro implicadas en la emoción.

De igual manera favorece a la concentración y estimula la atención. Estimula la memoria a corto y largo plazo; mueve a la reflexión, estimula el uso del lenguaje y facilita la comunicación verbal. La música puede movilizar y evocar sensaciones. Puede traer a la memoria olores, colores y modificar el estado de ánimo del oyente. Asimismo, la música contribuye al desarrollo de las habilidades sociales, fomenta las relaciones entre los miembros del grupo y facilita la conexión y el sentimiento de pertenencia al mismo.

\section{Usos de la música en el aula}

Bernabeu y Goldstein (2009) presentan distintas posibilidades del uso de la música en el aula.

a) Uso de la música en su función ambiental. Cuando hablan de la música en su función ambiental se refieren a utilizarla como una base sonora para crear en el aula una atmósfera propicia para el trabajo personal en silencio.

b) Uso de la música en su función informativa. Usar la música en su función informativa, hace referencia a las piezas musicales que transmiten por sí mismas toda la información necesaria.

c) Uso de la música en su función expresiva. Esta función, se refiere a crear el clima sonoro necesario para que la actividad que se propone realizar cumpla con su objetivo y permita a los alumnos expresar sus emociones más profundas.

d) Uso de la música en su función reflexiva. Hacer uso de la música en su función reflexiva se refiere a buscar esos espacios donde los alumnos puedan asociar libremente, sentir, emocionarse, 
vivir experiencias estéticas y espirituales y sacar de sí mismos lo que llevan dentro, sea conocido o no.

e) Uso de la música como elemento facilitador del movimiento. Es claro que la música facilita la actividad corporal y sirve para marcar el ritmo de movimiento que pretende que realicen los alumnos.

f) Uso de la música para crear contextos imaginarios. La música permite olvidarse de lo real por un tiempo y abre las puertas al mundo de la imaginación. Los autores de este estudio recomiendan utilizar este medio potente en el aula para que los alumnos puedan crear imágenes internas.

g) Uso de la música como elemento de anclaje memorístico. Cuando una persona asocia una determinada secuencia musical a un mensaje verbal, desarrolla todas sus capacidades racionales de comprensión lógica del texto y activa también todo su universo emocional. Esto le ayudará a comprender el mensaje de forma global y sintética de la mano de la razón y la emoción. Esta movilización de emociones que la música hace posible facilita el anclaje memorístico del sujeto.

h) Uso de la música como elemento evocador y anticipatorio. La música sirve para evocar algo ya que contiene el valor poético de la recurrencia, lo que ya ha aparecido una vez, vuelve a aparecer de nuevo. Así el receptor fija en su mente y cuerpo las experiencias y conocimientos adquiridos durante la sesión de clase. De igual manera, tiene un valor anticipatorio ya que puede contar con un tiempo para disponerse a la reflexión de lo que se va a exponer a continuación y se adelantan a las experiencias que siguen.

i) Uso de la música como elemento de encadenamiento y transición. La música sirve para marcar la transición de los distintos momentos en que se secuencia una clase. En una sesión de clase se puede utilizar para marcar el comienzo de las actividades y el final de la clase. De igual manera puede indicar la entrada en la relajación, la apertura y cierre del contexto imaginario.

A manera de síntesis, es importante mencionar que el educador debe dirigirse a la búsqueda de alternativas novedosas, para lograr el aprendizaje en sus alumnos. Sin importar el área académica a la que esté integrado, el maestro debe facilitar los procesos de enseñanza aprendizaje en sus alumnos brindándoles los instrumentos y herramientas necesarias para que puedan acceder al 
aprendizaje con mayor facilidad. De allí que, Bernabeu y Goldstein (2009) hacen referencia a la música como un medio eficiente para desarrollar en los alumnos muchas destrezas y habilidades.

\section{Metodología}

La metodología fue de tipo descriptiva, que según Hernández, Fernández y Baptista (2014), afirman que la investigación descriptiva es la que se orienta a redactar informes relacionados con el estado real de las personas, objeto situaciones o fenómenos tal cual se presentan en el momento de su recolección, describe lo que mide sin analizar inferencias ni verificar hipótesis. El con un enfoque epistemológico hermenéutico, en la que revisaron diferentes teorías relacionadas con el uso de la música como una estrategia de enseñanza aprendizaje en el nivel de educación básica escolar. La población estuvo constituida por 120 docentes de los distintos colegios de educación básica adscrito en la provincia de Manabí. El instrumento utilizado fue una lista de cotejo semi estructurado, el cual estuvo constituido por 8 ítems. Además, se observaron el ambiente pedagógico de las aulas de los distintos colegios visitados, así como la disposición de materiales de uso musical. La validez del instrumento fue realizada a través del criterio de expertos en el área y la confiabilidad se determinó a través del Coeficiente de La validez del instrumento fue realizada a través del criterio de expertos en el área y la confiabilidad se determinó a través del Coeficiente de Kuder Richarson para ítems dicotómicos, cuyo resultado fue de 0.87, considerado altamente significativo. La técnica de análisis fue la estadística descriptiva a través del paquete estadístico SPSS versión 23.

\section{Resultados}

Posterior a la aplicación del instrumento tipo lista de cotejo semi estructurado para conocer el uso de la música como una estrategia de enseñanza aprendizaje se pudo constatar lo siguiente: 
Tabla 1. Valor y uso de la música en docentes de educación básica.

\begin{tabular}{|l|c|c|c|c|}
\hline \multirow{2}{*}{ Análisis /alternativas } & \multicolumn{2}{|c|}{ SI } & \multicolumn{2}{c|}{ NO } \\
\cline { 2 - 5 } & FR & $\%$ & FR & $\%$ \\
\hline $\begin{array}{l}\text { Valora su gusto por la } \\
\text { música }\end{array}$ & 120 & 100 & 0 & 0 \\
\hline Utiliza la música en el aula & 46 & 38 & 74 & 62 \\
\hline
\end{tabular}

Fuente: Docentes de educación Básica de los distintos colegios.

Elaboración: Grupo de Investigación UTM (propia 2018).

En la tabla1, se indica que el total de los docentes encuestados, coincidieron en afirmar que si les gustaba la música, convirtiéndose en una posición favorable para ser usada como una estrategia pedagógica durante el proceso de enseñanza aprendizaje de sus alumnos. Sin embargo, apenas el $38 \%$ indico que en algún momento la utilizan para facilitar el proceso de enseñanza aprendizaje, debido a la poca información que poseen y manejan en la materia.

Tabla 2. Percepción de la motivación a través de la música en docentes de educación básica.

\begin{tabular}{|l|c|c|c|c|}
\hline \multirow{2}{*}{ Análisis /alternativas } & \multicolumn{2}{|c|}{ SI } & \multicolumn{2}{c|}{ NO } \\
\cline { 2 - 5 } & FR & $\%$ & FR & $\%$ \\
\hline $\begin{array}{l}\text { Considera que la música } \\
\text { motiva a sus alumnos } \\
\text { durante las clases. }\end{array}$ & 114 & 95 & 6 & 5 \\
\hline $\begin{array}{l}\text { Requiere formación } \\
\text { profesional en materia de } \\
\text { motivación para el uso de la } \\
\text { música en clases. }\end{array}$ & 118 & 98 & 2 & 2 \\
\hline
\end{tabular}

Fuente: Docentes de educación Básica de los distintos colegios. Elaboración: Grupo de Investigación UTM (propia 2018). 
En la tabla 2, se evidencia que el $95 \%$ de los docentes aseguran que cuando han manejado la música como una estrategia de enseñanza aprendizaje han observado mayor motivación e interés por parte de sus alumnos en adquirir nuevos conocimientos, pero su uso es limitado por no contar con recursos musicales suficiente en las instituciones, ni conocer su manejo y utilización. Por otro lado, el $98 \%$ indico que se requieren cursos de motivación docente ante el uso de la música para incluirlas dentro de las actividades planificadas de sus contenidos programáticos.

Tabla 3. Uso de la música como fondo y /o silenciar el trabajo en el aula.

\begin{tabular}{|l|c|c|c|c|}
\hline \multirow{2}{*}{ Análisis /alternativas } & \multicolumn{2}{|c|}{ SI } & \multicolumn{2}{c|}{ NO } \\
\cline { 2 - 5 } & FR & $\%$ & FR & $\%$ \\
\hline $\begin{array}{l}\text { Uso de fondo musical en } \\
\text { clases }\end{array}$ & 109 & 91 & 11 & 9 \\
\hline $\begin{array}{l}\text { Uso para silenciar el trabajo } \\
\text { en el aula }\end{array}$ & 34 & 28 & 86 & 72 \\
\hline
\end{tabular}

Fuente: Docentes de educación Básica de los distintos colegios.

Elaboración: Grupo de Investigación UTM (propia 2018).

En la tabla 3, se indica que el $91 \%$ de los docentes investigados, afirmaron que nunca han utilizado la música como fondo musical, ni de información y medio expresivo para que sus alumnos puedan asociar libremente, sentir, emocionarse, vivir experiencias estéticas y espirituales y sacar de sí mismos lo que llevan dentro, sea conocido o no. Solo el $28 \%$ indico, que en algún momento la han utilizado para lograr el trabajo de sus alumnos en silencio. 
Tabla 4. La música como elemento corporal -imaginario.

\begin{tabular}{|l|c|c|c|c|}
\hline \multirow{2}{*}{ Análisis /alternativas } & \multicolumn{2}{|c|}{ SI } & \multicolumn{2}{c|}{ NO } \\
\cline { 2 - 5 } & FR & $\%$ & FR & $\%$ \\
\hline $\begin{array}{l}\text { La música es utilizada en el aula } \\
\text { como un elemento corporal - } \\
\text { imaginario para sus alumnos }\end{array}$ & 37 & 31 & 83 & 69 \\
\hline $\begin{array}{l}\text { Recurre a la música para lograr } \\
\text { recordar en sus alumnos los } \\
\text { contenidos vistos en clase. }\end{array}$ & 34 & 28 & 86 & 72 \\
\hline
\end{tabular}

Fuente: Docentes de educación Básica de los distintos colegios.

Elaboración: Grupo de Investigación UTM (propia 2018).

Se indica en la tabla 4, que el $31 \%$ del total de los docentes investigados, habían utilizado la música como un elemento facilitador de actividades corporales a través de los contextos imaginarios propios de sus alumnos. Por otro lado, el $28 \%$ indicaron haberla utilizado como un medio para recordar algunos contenidos programáticos utilizando la asociación y capacidad relacional de sus alumnos.

\section{Conclusiones}

Existe la necesidad manifiesta por parte de los docentes investigados de recibir cursos de formación musical, en materia del uso de la misma como estrategias de facilitación para el proceso de enseñanza aprendizaje de sus alumnos, entendiendo que lo poco conocido ha sido por indagación de sus propias voluntades.

Se puede afirmar una escasa utilización, por parte de los docentes investigados, de la música como estrategia de enseñanza aprendizaje. También se constató que en muy pocas oportunidades se hace uso de la música como una función ambiental e imaginativa.

Entre los investigados, se constató la efectividad de la música como una estrategia del trabajo en silencio y de movimientos corporales por parte de los educandos, la cual solo es utilizada por un porcentaje casi indivisible de docentes. Igual tratamiento de uso se da su utilización como elemento de asociación y capacidad relacional entre sus alumnos. 
Este trabajo investigativo contribuye a la línea de investigación, pedagogía y educación, y a la sub línea, metodologías de enseñanza y aprendizaje, dirigido a mejorar los entornos virtuales como herramienta de aprendizaje colaborativo.

\section{Referencias Bibliográficas}

Bernabeu N y Golstein A. (2009). Creatividad y aprendizaje. ISBN 10: 8427716281 / ISBN 13: 9788427716285 . Editorial: Narcea

Díaz, F., Hernández G. (2003). Estrategias Docente para el Aprendizaje Significativo. España. Ediciones Mc Graw - Hill.

Díaz, I. (2014). Integración de la Música en el Currículo Escolar. Documento en Línea. Recuperado en: http:/wwww.Nome.coqui.net/senderomusical escolar. Consultado 01 noviembre 2006.

Hernández, Fernández y Baptista (2014). Metodología de la Investigación. Tercera Edición. México. Editorial Me Graw Hill.

González, O. (2008). La Canción como recurso de Educación Intercultural en la Escuela: Cancionero Intercultural. En M. A. Ortiz (Coord.), Música. Arte. Diálogo. Civilización. (pp. 27-65). Coimbra (Portugal): Center for Intercultural Music Arts y Grupo de Investigación Hum-742.

González, L (2008). Algunas Estrategias para el Proceso Enseñanza-Aprendizaje. Documento en Línea. Recuperado en: http:/www.monografías.com/trabajo36/html.

López, M. (2007). La música en centros de educación infantil 3-6 años de Galicia e Inglaterra. [En red] Recuperado en: http://books.google.es/books?id=UUGmrVCupiAC\&printsec=frontcover\& $\mathrm{dq}=\mathrm{la}+$ musica+en+centros+de+educacion+infantil $+3-$ 6+a\%C3\%B1os\&hl=es\&sa=X\&ei=TZ1YUqiTF7ew4APS0YHYCA\&ved=0 CEEQ6AEwAA\#v=onepage $\& q=1 \mathrm{a} \% 20$ musica $\% 20 \mathrm{en} \% 20$ centros $\% 20 \mathrm{de}$ $\% 20$ educacion $\% 20$ infantil $\% 203-6 \% 20 \mathrm{a} \% \mathrm{C} 3 \% \mathrm{~B} 1$ os\&f=false 
Montero Castellano, O. (2011). Superaprendizaje en la Educación: Bases del Superaprendizaje. Documento en Línea. Recuperado en: http:/www.maixmail.com/curso/vida/superaprendizaje. Consultado 05 noviembre 2006.

Soledad, M. y Carvajal, D. (2015). El arte como herramienta educativa: un potencial para trabajar la inclusión y la diversidad. Revista para el aula, 14 (pp.47-48). Santa Cruz de Tenerife: Ediciones IDEA.

UNICEF (2001). Hacia el desarrollo de escuelas inclusivas. En HINENI, UNESCO y UNICEF. Ciclo de debates: Inclusión de niños con discapacidad en la escuela regular, Santiago de Chile. 